\title{
The Effect of Amount of Alkaline Solution on Fly ash and Metakaolin based Geopolymer Mortar Properties
}

\author{
Gökhan Görhan, Gökhan Kürklü
}

\begin{abstract}
This study investigated the effect of four different amounts of alkaline solution $(240,270,390$ and $435 \mathrm{ml})$ used in the production of metakaolin and fly ash-based geopolymer mortar on sample properties. In the preparation of geopolymer mortars, metakaolin obtained by the sintering at $1000{ }^{\circ} \mathrm{C}$ of kaolin clay and fly ash obtained from Kütahya Seyit Ömer (Turkey) thermal power plant was used. Geopolymer mortars were cast into $40 \times 40 \times 160 \mathrm{~mm}$ molds and cured for $5 \mathrm{~h}$ at $80^{\circ} \mathrm{C}$ in a laboratory-type oven. The curing process of the samples was completed, and they were subjected to physical and mechanical tests at the end of the 7 th day following their production. Consequently, it was determined that the ideal amount of alkali solution in the preparation of the geopolymer mortar samples was $270 \mathrm{ml}$. In addition, the flexural and compressive strength values of the geopolymer mortars produced using $270 \mathrm{ml}$ alkaline solution were 4.9 MPa and 21.8 MPa, respectively.
\end{abstract}

Keywords - fly ash, metakaolin, alkaline solution, geopolymer, mortar.

\section{Introduction}

There has been an increase in the demand for concrete as a building material. However, the production of cement used in the production of concrete leads to environmental pollution and limestone raw material is reduced. Approximately one ton of $\mathrm{CO}_{2}$ is released for the production of one ton of normal Portland cement [1]. Another negative aspect of cementitious composites is that they do not show sufficient resistance to many external influences [2].

One of the studies on the production of binding agents without the use of Portland cement is uses the activation of industrial waste, such as blast furnace slag and fly ash, and pozzolans such as zeolite and metakaolin with alkalies. With a network of inorganic molecules called geopolymer, a wide range of material characterization can be accomplished through these activations [3].

Gökhan GÖRHAN

Afyon Kocatepe University TURKEY
Geopolymerization is composed of amorphous, $\mathrm{Si}-\mathrm{O}-\mathrm{Al}$ and $\mathrm{Si}-\mathrm{O}-\mathrm{Si}$ bonds with a semi-crystalline polymeric structure of solid aluminosilicate oxides and alkali metal silicate solutions in a high alkaline environment and at a mild temperature [4]. However, the geopolymer reaction mechanism is not fully understood. Most recommended mechanisms include the steps of a dissolution, transport or orientation, as well as polycondensation [5].

The literature contains some scientific data from previous studies regarding the evaluation of the chemical and physical properties of geopolymer. However, extensive research is needed to determine the fracture strength of this material, the effect of different curing regimes on the hardening rate, and the concentration and dosage of alkaline [6].

This study investigated the effect of different amounts of alkaline solution used in the production of metakaolin and fly ash-based geopolymer mortar activated with $12 \mathrm{M} \mathrm{NaOH}$ on the samples.

\section{Material and Method}

\section{A. Materials}

Fly ash from Kütahya Seyit Ömer (Turkey) thermal power plant and kaolin clay from the Kale Mine were used in the preparation of geopolymer mortar samples. Prior to use in the production of geopolymer mortar, kaolin clay was calcined in a laboratory-type electric arc furnace for $1 \mathrm{~h}$ at $1000{ }^{\circ} \mathrm{C}$ and at the final temperature and converted to metakaolin. Prior to the addition to the mixture, the metakaolin material was milled in $\mathrm{a}$ in a laboratory-type ball into a mill fineness of $-250 \mu \mathrm{m}$ and then sieved. Table 1 shows $\mathrm{d}_{10}, \mathrm{~d}_{50}$ and $\mathrm{d}_{90}$ values of laser particle size analysis of the fly ash and metakaolin.

According to the XRF analysis of the fly ash, its total values of $\mathrm{SiO}_{2}+\mathrm{Al}_{2} \mathrm{O}_{3}+\mathrm{Fe}_{2} \mathrm{O}_{3}$ is $81.71 \%$ and the value of $\mathrm{CaO}$ is $4.31 \%$. The fly ash used in line with this data is class $\mathrm{F}$ fly ash according to ASTM C 618-08a [7]. Silica / alumina ratio $\left(\mathrm{SiO}_{2} / \mathrm{Al}_{2} \mathrm{O}_{3}\right)$ by mass of the fly ash is 2.69 (Table 2). According to the data obtained from the XRD analysis of the fly ash and metakaolin, fly ash contains minerals such as quartz, magnetite, hematite and albite while metakaolin contains minerals such as quartz and mullite. 
Proc. of the Second Intl. Conf. on Advances in Bio-Informatics and Environmental Engineering - ICABEE 2015

Copyright (C) Institute of Research Engineers and Doctors, USA .All rights reserved.

ISBN: 978-1-63248-043-9 doi: 10.15224/ 978-1-63248-043-9-36

TABLE I. PARTICLE SIZE ANALYSIS OF THE MATERIALS

\begin{tabular}{|c|c|c|c|}
\hline \multirow{2}{*}{ Sample } & \multicolumn{3}{|c|}{ Particle size } \\
\cline { 2 - 4 } & $\mathbf{d}_{\mathbf{1 0}}(\boldsymbol{\mu \mathbf { m } )}$ & $\mathbf{d}_{\mathbf{5 0}}(\boldsymbol{\mu \mathbf { m }})$ & $\mathbf{d}_{\mathbf{9 0}}(\boldsymbol{\mu m})$ \\
\hline Fly ash & 15.96 & 84.75 & 231.33 \\
\hline Metakaolin & 1.18 & 11.69 & 56.34 \\
\hline
\end{tabular}

TABLE II. CHEMICAL COMPOSITION (XRF) OF THE FLY ASH AND METAKAOLIN

\begin{tabular}{|c|c|c|}
\hline \multirow{2}{*}{ Oxide (\%) } & \multicolumn{2}{|c|}{ Materials } \\
\cline { 2 - 3 } & Metakaolin & Fly ash \\
\hline $\mathrm{SiO}_{2}$ & 61.61 & 49.81 \\
\hline $\mathrm{Al}_{2} \mathrm{O}_{3}$ & 35.02 & 18.50 \\
\hline $\mathrm{Fe}_{2} \mathrm{O}_{3}$ & 0.89 & 13.40 \\
\hline $\mathrm{MgO}$ & 0.06 & 4.56 \\
\hline $\mathrm{Na}_{2} \mathrm{O}$ & 0.03 & 0.55 \\
\hline $\mathrm{K}_{2} \mathrm{O}$ & 0.50 & 1.84 \\
\hline $\mathrm{SO}_{3}$ & 0.08 & 1.45 \\
\hline $\mathrm{CaO}$ & 0.15 & 4.31 \\
\hline $\mathrm{LOI}$ & 0.27 & 3.52 \\
\hline $\mathrm{Total}$ & 98.61 & 97.94 \\
\hline
\end{tabular}

$\mathrm{NaOH}$ and sodium silicate solution $\left(\mathrm{Na}_{2} \mathrm{SiO}_{3}\right)$ were used as the alkaline activator in the preparation of the geopolymer mortars. The properties of these materials are presented in Table 3.

TABLE III. ALKALINE ACTIVAYORS AND THEIR PROPERTIES

\begin{tabular}{|c|c|}
\hline $\begin{array}{c}\text { Sodium silicate solution } \\
\left(\mathrm{Na}_{2} \mathrm{SiO}_{3}\right)(\mathbf{S S})\end{array}$ & $\begin{array}{c}\text { Sodium hydroxide } \\
(\mathbf{N a O H})\end{array}$ \\
\hline $\mathrm{Na}_{2} \mathrm{O}: 26.98(\%)$ & $\mathrm{M}: 40 \mathrm{~g} / \mathrm{mol}$ \\
\hline $\mathrm{SiO}_{2}: 8.77(\%)$ & $\mathrm{NaOH} \geq 99,0(\%)$ \\
\hline
\end{tabular}

\section{B. Procedure}

Liquid at four different rates was used in order to observe the effect of alkaline solutions in geopolymer mortars. $\mathrm{NaOH}$ which was in a pellet state during the preparation of alkaline solutions, was dissolved in purified water and made into a $12 \mathrm{M}$ concentration. The $\mathrm{SS} / \mathrm{NaOH}$ ratio by volume of the alkaline solutions, in which sodium silicate solution and $\mathrm{NaOH}$ were used together was 2 . Geopolymer mortars were prepared by adding alkaline solution and standard sand to the fly ash and metakaolin materials and mixed in an automatically programmable cement mixer. Afterwards, the geopolymer mortar was cast in steel molds (size 40x40x160 $\mathrm{mm}$ ) and vibrated. Later on, the samples were placed in a laboratory type oven in order to perform a thermal curing process and they were subjected to thermal curing for $5 \mathrm{~h}$ at 80 ${ }^{\circ} \mathrm{C}$. Table 4 shows the materials and mixture ratios used in the preparation of the geopolymer mortars.
TABLE IV. MIXTURE RATIOS OF THE MORTARS

\begin{tabular}{|l|c|c|c|c|}
\hline \multirow{2}{*}{\multicolumn{1}{|c|}{ Materials }} & \multicolumn{4}{|c|}{ Mixtures } \\
\cline { 2 - 5 } & $\mathbf{1}$ & $\mathbf{2}$ & $\mathbf{3}$ & $\mathbf{4}$ \\
\hline $\begin{array}{l}\text { Alkaline solution } \\
(\mathrm{ml})\end{array}$ & 240 & 270 & 390 & 435 \\
\hline Fly ash (gr) & 270 & 270 & 270 & 270 \\
\hline Metakaolin (gr) & 180 & 180 & 180 & 180 \\
\hline Standard sand (gr) & 1350 & 1350 & 1350 & 1350 \\
\hline
\end{tabular}

\section{Tests}

After the completion of the thermal curing, the samples were stored in the laboratory environment until the day of the tests. 7-day geopolymer mortars were used in the tests. The mean values of three samples from each of the sample groups were taken for the physical tests and the compressive strength tests. The apparent porosity, unit weight and apparent density values of the samples were determined according to TS EN 772-4 [8] and their water absorption values were determined according to TS EN 771-1 [9]. The mechanical properties of the geopolymer mortar were determined according to TS EN 196-1 [10].

\section{Result and Discussion}

The data obtained from the geopolymer mortars as physical and mechanical properties are separately presented and discussed in this section.

The apparent porosity and water absorption values (Figure 1) of the geopolymer mortars showed variations depending on the amount of the alkaline solution used. The alkaline solution led to a decrease in the apparent porosity and water absorption rates up to a certain value, while these values increased again with higher amounts of alkaline solution. Of all the samples, the lowest water absorption rate and apparent porosity values were obtained from the mortar samples with $270 \mathrm{ml}$ alkaline solution. From the second mixture onwards, the apparent porosity and water absorption rates of the samples increased with an increase in the amount of alkaline solution used in the production of the geopolymer mortars. It is believed that the porosity rate of the samples increased with an increase in the amount of the solution used in the production and led to an increase in the values of the apparent porosity and water absorption. It is also believed that the apparent porosity and water absorption values of the samples produced with $240 \mathrm{ml}$ alkaline solution, were the highest due to the fact that the materials could not be sufficiently compressed to the molds. 
Proc. of the Second Intl. Conf. on Advances in Bio-Informatics and Environmental Engineering - ICABEE 2015

Copyright $($ Institute of Research Engineers and Doctors, USA .All rights reserved.

ISBN: 978-1-63248-043-9 doi: 10.15224/ 978-1-63248-043-9-36

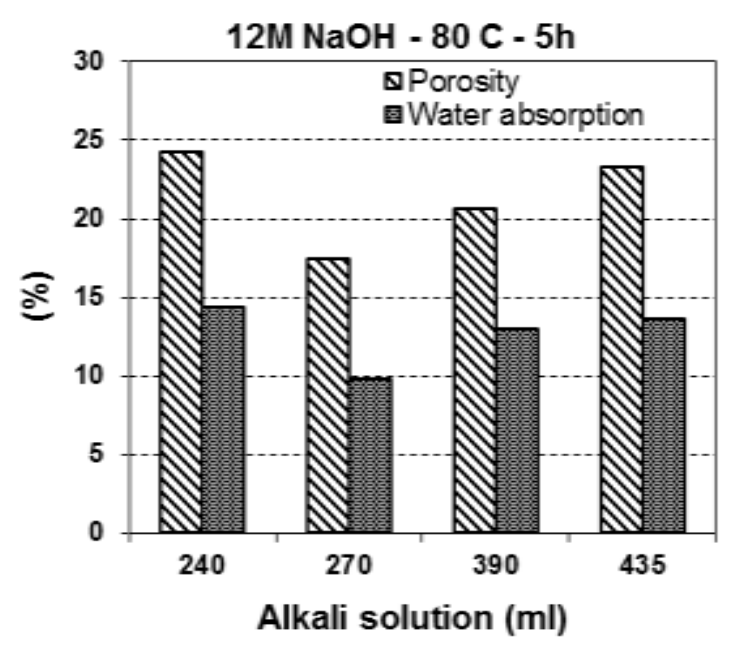

Figure 1. The apparent porosity and water absorption rates of the mortars.

It was determined that mixture sample No. 2 which had the lowest water absorption and porosity rates had the highest unite weight. In addition, the lowest bulk density values were obtained from mixture sample No. 3. On the whole, it was observed that the amounts of alkaline solution used in the production of the geopolymer mortars had no significant effect on the density values (Figure 2).

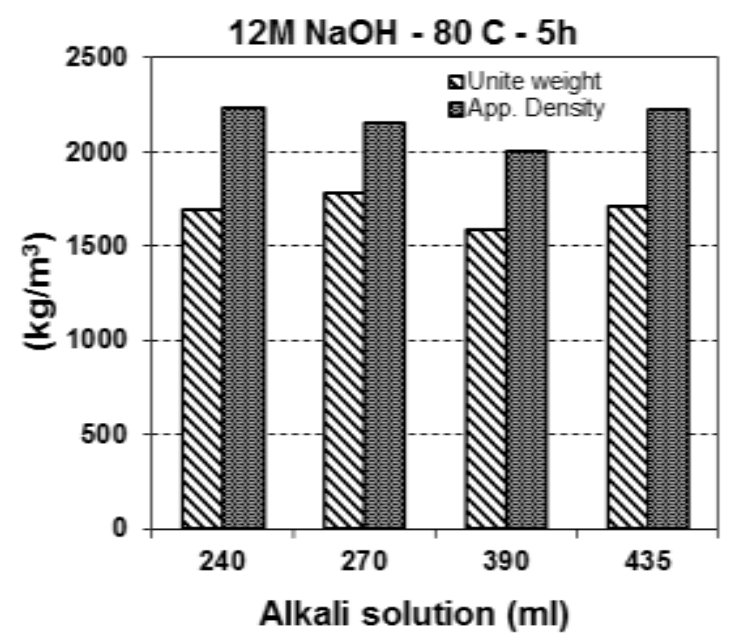

Figure 2. The bulk density and apparent porosity values of the mortars.

Figure 3 shows the flexural and compressive strength values of the mortars. According to the data obtained, it was observed that the use of alkali solution up to $270 \mathrm{ml}$, in the preparation of the geopolymer mortar samples, significantly increased the flexural and compressive strength values. On the other hand, when the amount of alkaline solution used was between 390 and $435 \mathrm{ml}$, it led to a significant reduction in the flexural and compressive strength values of the samples

It is believed that an excessive amount of alkaline solution used in the preparation of the geopolymer mortars prevents adequate geopolymerization in the matrix and therefore the mechanical properties do not fully develop.

When the amount of alkaline solution used in the preparation of the geopolymer mortars was $270 \mathrm{ml}$, the highest flexural and compressive strength rates were 4.9 MPa and 21.8 $\mathrm{MPa}$, respectively.

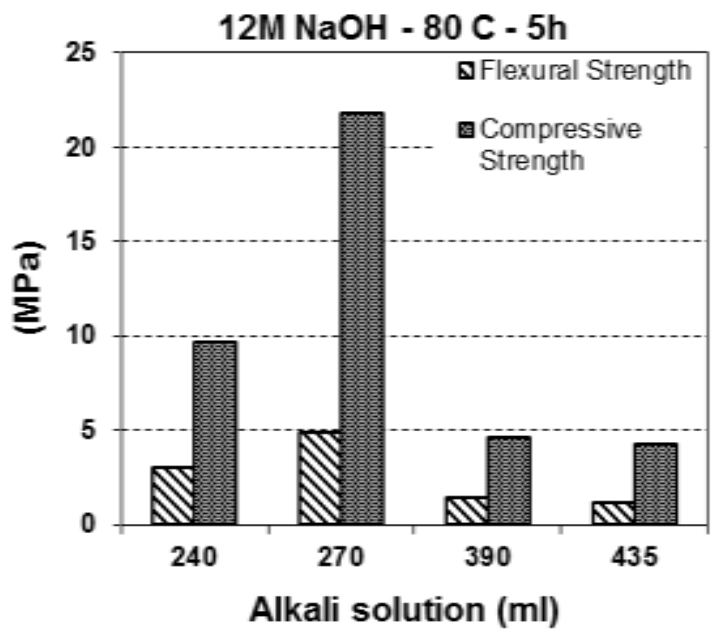

Figure 3. Flexural and compressive strength values of the mortars.

\section{Conclusion}

According to the physical and mechanical properties obtained from the mortar samples produced using four different amounts of alkaline solution, $270 \mathrm{ml}$. alkaline solution was determined to be the most ideal amount for the preparation of the geopolymer mortar samples. In addition, the flexural and compressive strength rates of the geopolymer mortars produced using $270 \mathrm{ml}$ alkaline solution were $4.9 \mathrm{MPa}$ and $21.8 \mathrm{MPa}$, respectively.

\section{Acknowledgment}

The authors would like to thank TÜBITAK for providing financial support for this research (TÜBİTAK Project Number: 213 M 294).

\section{References}

[1] J. Davidovits, "GlobalWarming Impact on the Cement and Aggregates Industries", World Resource Review, 6(2), 263-278, 1994.

[2] S. Aydın, "Alkalilerle Aktive Edilmiş Yüksek Fırın Cürufu Bağlayıcılı Lifli Kompozit Geliştirilmesi”, Doktora Tezi, Dokuz Eylül Üniversitesi, İzmir-Türkiye, 2010.

[3] Anonym, "What Is a Geopolymer?", Geopolymer Institute, Accessed on January 24, 2014, at http://www.geopolymer.org/science/introduction.

[4] D. Dimas, I. Giannopoulou and D. Panias, "Polymerization in sodium silicate solutions: a fundamental process in geopolymerization technology", J. Mater Sci., 44, 3719-3730, 2009.

[5] J. C. Swanepoel and C. A. Strydom, "Utilisation of fly ash in a geopolymeric material," Applied Geochemistry, 17, 1143-1148, 2002.

[6] K. Srinivasan and A. Sivakumar, "Geopolymer Binders: A Need for Future Concrete Construction", Hindawi Publishing Corporation, ISRN Polymer Science, Volume 2013, Article ID 509185, 8 pages http://dx.doi.org/10.1155/2013/509185.

[7] ASTM C 618, 2003 Standard specification for fly ash and raw or calcined natural pozzolan for use as a mineral admixture in Portland cement concrete. American Society for Testing and Materials. West Conshohocken (PA, USA): ASTM International. 
Proc. of the Second Intl. Conf. on Advances in Bio-Informatics and Environmental Engineering - ICABEE 2015

Copyright $($ Institute of Research Engineers and Doctors, USA .All rights reserved.

ISBN: 978-1-63248-043-9 doi: 10.15224/ 978-1-63248-043-9-36

[8] TS EN 772-4. Kagir Birimler, deney metotları - Bölüm 4: Tabii taş kâgir birimlerin toplam ve görünen porozitesi ile bosluksuz ve bosluklu birim hacim kütlesinin tayini (Methods of test for masonry units - Part 4: Determination of real and bulk density and of total and open porosity for natural stone masonry units) 2000. TSE. Ankara-Turkey.

[9] TS EN 771-1. Kagir Birimler, Özellikler- Bölüm 1: Kil kâgir birimler (Tuğlalar) (Specification for masonry units - Part 1: Clay masonry units) 2005. TSE. Ankara-Turkey.

[10] TS EN 196-1. Çimento Deney Metotları- Bölüm 1: Dayanım (Methods of testing cement - Part 1: Determination of strength) 2002. TSE. Ankara - Turkey. 